\title{
Project Management on Code Coverage Analysis
}

\author{
Pinghua Jiang \\ The Center of Library and information \\ Qingdao Ocean Shipping Mariners College \\ Qingdao, China \\ pjiang9@163.com
}

\begin{abstract}
The code coverage analysis of large-scale software is a project that needs management skills to accomplish. The paper does research on how to apply Project Management Body of Knowledge (PMBOK) to the code coverage analysis based on its techniques and process. The initiating process group focuses on three activities, including identifying stakeholders, defining initial scope and selecting project manager. In the planning process group, the schedule and work breakdown structure of two runs for code coverage analysis are made. The executing process group mainly discusses about creating the project team and using what kinds of organizational process assets. In the monitoring and controlling process group, the paper focuses on two processes induding the change control process and verifying the acceptance of deliverables. How to conclude the project is presented in the dosing process group. In the end, the paper point out other fields that PMBOK can be applied in a similar way.
\end{abstract}

Keywords-Code Coverage Analysis; Software; Project Management; PMBOK ; Process Group;

\section{INTRODUCTION}

Code coverage analysis includes main static analysis and dynamic coverage analysis. Main static analysis searches the source code for any programming standards violations. Dynamic coverage analysis explores the semantics of the program-under-test via test data selection. It uses control and data flow models and compares them with the actual control and data flow as the program executes during testing. Dynamic coverage analysis is the main effort of code coverage analysis.

Code coverage analysis is popular in highly safe and reliable software, such as the airborne software. It is usually performed on source code rather than the object code[1]. Large-scale software is made up of thousands of source files, the code coverage analysis could be a time consuming and complex task to accomplish. The Project Management Body of Knowledge (PMBOK) Guide fifth edition[2] defines that a project is a temporary endeavor undertaken to create a unique product, service or result. Researchers can take the code coverage analysis as a project and apply the project management techniques to have a significant impact on its success.

\section{INITIATING PROCESS GROUP}

The PMBOK defines several activities in the in itiat ing process group of a project. For code coverage analysis, the key activities include identifying stakeholders, defining the initial scope, and selecting the project manager.

\section{A. Identify Stakeholders}

Stakeholders are persons or organizations that have influence on the decision making, activities, or result of the project. They include all members of the project team as well as all interested entities internal or external. The key purpose of the initiating process group is to align the stakeholders' expectations with the project purpose. The project team members will be discussed later. Other than that, the most important stakeholders are the Program Manger (PM) and the Designated Engineering Representative (DER).

PM is responsible for the overall scope, schedule, financial, and quality performance on the program. A program is usually comprised of several related projects. The PM's main concern is the schedule and cost of code coverage analys is.

DER is on behalf of the software company side to communicate with the authority for the certification of the software. DER's main concern is the quality of the code coverage result. DER expects the coverage report is reasonable and reliable.

\section{B. Define initial scope}

There are many types of code coverage. Three common ones are Statement Coverage (SC), Condition/Decision Coverage (DC) and Modified Condition/Decision Coverage (MC/DC).

The scope of code coverage analysis is largely depended on the industry standards. Take airborne software as an example, DO-178B[3] defines the requirements for coverage analysis according to software level. Software level is based upon the contribution of software to potential failure conditions as determined by the system safety assess process. DO-178B defines five levels for airborne software from A to E. DO-178B Table A-7 defines the following coverage requirements for different software levels.

(1) Level A: MC/DC, DC and SC are achieved. The objective shall be satisfied with independence.

(2) Level B: DC and SC are achieved. The objective shall be satisfied with independence.

(3) Level C: SC is achieved.

To be satisfied with independence means that who does the code coverage analysis shall be personally or organizationally independent with the source code 
developer. The software level determines what kind of coverage shall be achieved. There are situations that some code is never excised through Requirement-Based Testing (RBT). There are some reasons for it. If the reasons are acceptable to certification authorities, a coverage analysis can be provided to explain the coverage miss[4]. With combination of RBT and coverage analysis, the coverage percent of all code shall be one hundred. This brings to the completion and success of SCA.

\section{Select project manager}

The best organizational structure for code coverage analysis is the strong matrix organizations. The project manager is a full-time role with considerable authority. The project manager can be assigned to a software engineer or verification engineer. He or she shall have the back ground of PMBOK. In addition, he or she better knows some techniques of code coverage analys is.

\section{PLANNING PROCESS GROUP}

PMBOK points out that the project management plan and project documents developed as outputs form the planning process group will explore all aspects of the scope, time, cost, quality, communications, human resources, risks, procurements and stakeholder engagement. For code coverage analys is, the key plan follows.

\section{A. schedule plan}

The entry condition for starting code coverage analys is shall be analyzed first. For airborne software, there are four Stage of Involvements (SOIs) held by certification authorities: planning review, development review, verification review and final review[5]. The third SOI has the task to ensure analyses (including timing, me mory, test coverage, structural coverage) are being performed, as required by $\mathrm{DO}-178 \mathrm{~B}$. Therefore, one entry condition of code coverage analysis is that the second SOI has been completed.

Other entry conditions include: the requirements development is complete; test cases and test procedures development is complete; all tests are executed without failures.

It is better to have code coverage analys is done at least two runs. The initial run of code coverage analys is is right after an internal formal baseline of code and test cases when a dry run of hosting testing shows no unacceptable failures. There may be some coverage inadequacies in the first run of code coverage analys is due to code structure defects or missing test cases. Means are taken to resolve these inadequacies with updates on code, test cases, test scripts and even requirements. Formal baseline is established after that. Formal target testing is to be run with no failures. Then, the formal run of code coverage analysis is held to generate the final coverage analysis report.

\section{B. Work Breakdown Structure}

To create the Work Breakdown Structure (W BS) is the process of subdividing project deliverables and project work into smaller, more manageable components. There are two runs for code coverage analysis.

The WBS for the first run of code coverage analysis can be the following five steps.
Firstly set up test environment. Secondly prepare the application to be tested. Thirdly run RBT. Fourthly analyze the coverage report. Fifthly resolve the coverage inadequacies.

In the second run, the first three steps are the same. The last two steps are replaced by updating the coverage report.

\section{EXECUTING PROCESS GROUP}

The PMBOK states that the executing process group consists of those processes performed to complete the work defined in the project management plan to satisfy the project specifications. For code coverage analysis, the main processes include creating a project team and executing the work.

\section{A. Create project team}

The project team is made up of project manager, verification engineers, software engineers, system engineers and quality engineer.

The project manager is responsible for the project management. He or She reports to program manager.

Verification engineer, sometime called test engineer, is responsible for the test case design, test procedure development and testing. The verification engineers are the main members of the project, usually working full-time during the project lifecycle. They set up the test environments, execute the RBT, analyze the coverage report, and find the reasons for coverage inadequacies. They also provide the final coverage report.

Software engineer is responsible for the software design, code development and review. Software engineer is the author and maintainer for software requirements. The software engineers work half-time on the project. They might help the verification engineer to compile and link the instrumented code. They are involved in the change control procedures on software change request. They provide the analysis for the acceptable coverage inadequacies for software reason.

System engineer is responsible for the system design, system verification and review. System engineer is the author and maintainer for system requirements. The system engineers work on the project occasionally. They are involved in the change control procedures on system change request. They provide the analysis for the acceptable cover analys is inadequacies for systemreason.

The quality engineer works on the project occasionally, he or she usually audits some reviews to check the process.

\section{B. Execute code coverage analysis}

During executing the code coverage analysis, it is important to use and update the organizational process assets. Three types of the as sets are addressed here.

The first one is the process document. The objective of the document is to define verification environments needed to meet the requirements found in the industry standards such as DO-178B. The document also defines the specific procedures for the used coverage analys is tool such as IBM Rational Test RealTime Studio, Bullseye or LDRA Testbed.

The second one is the template for tracking artifacts.

It is helpful to have the document to hold the tracking and status of the work effort. The following pieces of information shall be captured in the document, as they are 
needed for traceability purposes. It includes tests that were run, revision of repository that holds the above tests, revision or label of the repository that holds the source code, the name of the resulting test log file, the efforts for running the test, pass or fail of the tests, other notes

The third one is the analysis template. It is helpful to have a consistent way to capture any analysis that is completed. The following pieces of information shall be captured in the analysis document as they are needed to show a complete analysis for any given issue. It includes function where the coverage miss occurred, whether the miss was SC, DC, or MC/DC or any combination thereof, what the miss was and the analysis.

\section{MONIT ORING AND CONTROLLING PROCESS GROUP}

PMBOK states that the monitoring and controlling process group consis ts of those processes required to track, review and orchestrate the progress and performance of the project; identify any areas in which changes to the plan are required, and initiate the corresponding changes.

There are many monitoring means, such as weekly meeting, time card recoding and analysis, cost evaluation, schedule monitoring. The paper will just focus on two processes including the change control process and verifying the acceptance of the deliverables.

\section{A. Change control process}

Change control procedures include the steps by which official organization standards, policies, plans, and procedures, or any project documents will be modified and how any changes will be approved and validated.

As to code coverage analysis, the following are typical situations and solutions.

\section{1) Redundant code}

Redundant code happens while there is some unnecessary code with no corresponding requirements. The code need to be removed to resolve the coverage inadequacies.

As usual, the verification engineer who does the code coverage analysis is the finder. He or she issues a change request. The project manager and software engineer will evaluate the change request. If it is approved, software engineer will be the implementer of the request. After the change done, the implementer shall setup a peer review to invite peers for checking the work. The finder must be one of the reviewers.

\section{2) Inadequate test cases or test procedures}

In the situation, test cases or test procedures are not complete regarding the requirements. It is necessary to write more test cases or test procedures to resolve the coverage inadequacy.

Same as above, the verification engineer who does the code coverage analysis is the finder. He or she issues a change request. The project manager and the other verification engineers will evaluate the change request. If it is approved, some verification engineer will be the implementer of the request. After the change done, the implementer shall setup a peer review. The finder must be one of the reviewers.

\section{3) Code and Requirement mismatch}

The situation does not happen often. The test cases and procedures are designed based on require ments. If the code mismatch requirement, coverage inadequacy will occur. In this situation, decision is made after careful investigation. Either code or requirement needs to be updated to resolve the inadequacy.

The finder issues a change request. The project manager is aware of it. He will hold a meeting to invite software and system engineers to find out it is requirements problem or code problem. If it is the code problem, the software engineer will be the implementer. If it is the requirements problem, the change request shall be put forward to the Change Control Board (CCB) for reviewing. If it is approved, the requirement owner, either software engineer or system engineer, will be the implementer. The finder is one of the reviewers for the change.

\section{B. Verify the deliverables.}

Before the final code coverage analys is is delivered to DER, there is a process to verify the acceptance of the deliverables. The process could be an overall peer review. The key roles of peer review can be set up as shown in Table 1.

TABLE I. PEER REVIEW ROLES

\begin{tabular}{|c|c|c|}
\hline Attendees & Roles & Responsibilities \\
\hline $\begin{array}{c}\text { Verification } \\
\text { engineer(s) }\end{array}$ & Author & $\begin{array}{c}\text { Set up peer reviews. Provides } \\
\text { the final code coverage report } \\
\text { and related artifacts. }\end{array}$ \\
\hline $\begin{array}{c}\text { Software } \\
\text { engineer(s) }\end{array}$ & Reviewer & $\begin{array}{c}\text { Review the report from } \\
\text { software perspective. }\end{array}$ \\
\hline $\begin{array}{c}\text { Verification } \\
\text { engineer(s) other } \\
\text { than the author }\end{array}$ & Reviewer & $\begin{array}{c}\text { Review the report from testing } \\
\text { perspective }\end{array}$ \\
\hline $\begin{array}{c}\text { System } \\
\text { engineer(s) }\end{array}$ & Reviewer & $\begin{array}{c}\text { Review the report from system } \\
\text { perspective }\end{array}$ \\
\hline $\begin{array}{c}\text { Quality engineer } \\
\text { Quality } \\
\text { assurance }\end{array}$ & $\begin{array}{c}\text { Review the report from } \\
\text { standard and process } \\
\text { perspective. }\end{array}$ \\
\hline
\end{tabular}

The checklist for the peer review is as the following.

(1) In the report, configuration is consistent. The version or revision of software repository matches that of test repository.

(2) In the report, the analysis for coverage inadequacies is reasonable and acceptable.

(3) All code is covered either by RBT or by analysis.

\section{CLOSING PROCESS GROUP}

The PMBOK states that the closing process group consists of those processes performed to conclude all activities across all the project management process groups to formally complete the project, phase or contractual obligation. As to the code coverage analysis, there are three things to do.

The first one is to deliver the final coverage report including all analysis and related artifacts to the DER. Usually the report is package together with other software verification results.

The second one is to update the organizational process assets. The update on organizational process assets happens all through the whole project. In the closing process group, it shall be updated, categorized, organized, and archived.

The last one is to dismiss the project team and release all the human resources and equipment resources. 


\section{SUMMARY}

The theory the paper presents has been taken into practice on code coverage analys is of flight control system of some program in Rockwell Collins Company in U.S. The project was accomplished with great success. Other projects such as data coupling and control coupling [6], software host and target testing are similar to code coverage analysis from process perspective. The PMBOK can be applied on them in the similar way.

\section{REFERENCES}

[1] CAST-12 paper, entitled Guidelines for Approving Source Code to Object Code Traceability, Certification Authorities Soft ware Team, June, 2002.
[2] A Guide to the Project Management Body of Knowledge. Fifth Edition. Pennsylvania: Project Management Institute, 2013. Reference to a chapter in an edited book:

[3] RTCA/DO 178B, Software Considerations in Airborne Systems and Equipment Certification, Washington. DC: RTCA, December 1992.

[4] Gifford, W., Structural coverage analy sis method, Digit al Avionics Systems Conference, 1996, 15th AIAA/IEEE, IEEE Conference publications, 1996

[5] Conducting Software Reviews Prior to Certification- Job Aid, Aircraft certification service Rev1, Federal Aviation Administration, January, 2004.

[6] CAST-19 paper, Clarification of Structural Coverage Analyses of Data Coupling and Control Coupling (Rev 2), Certification Authorities Software Team, January, 2004. 